\title{
Influence on Time to Cryopreservation in Umbilical Cord Blood Units
}

\author{
Isidro Prat-Arrojo, Laura Ponce-Verdugo, María del Carmen Hernández-Lamas, \\ Rebeca Rodríguez-Pena, Cristina Antúnez, Francisco Sánchez-Gordo, \\ Gracia García-Gemar, Pilar Gómez-Maldonado
}

Umbilical Cord Blood Bank Andalusia, Malaga, Spain.

Email: laura.ponce.sspa@juntadeandalucia.es

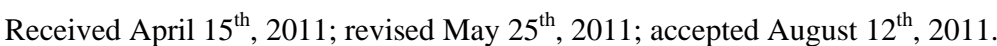

\begin{abstract}
It is accepted that the Umbilical Cord Blood (UCB) units can be cryopreserved to $48 \mathrm{~h}$ after their harvest and the delay in this procedure influences the final quality. The aim of this study was to determine the influence on time to cryopreservation in Umbilical Cord Blood Units. A selection of the 2134 samples arrived to the UCB Bank from 36 Andalusian linked hospitals was analyzed for a period of six months. The date and hour of collection, hospital of origin, time in the hospital, time of transport, time of arrival to the bank to cryopreservation, viability and CD34+ cells were determined. Our results showed that the median time from harvest to cryopreservation was $27.9 \mathrm{~h}$. However, a great variability was found (range: 5.3 to $47.6 \mathrm{~h}$ ), which was dependent on transport variables: time from collection to leave the hospital (median 12.6 h, range: 0.1 - 28.8), time of transport from hospital to UCB Bank (median 1.8 h, range: 0.1 - 20.6) and time kept in the bank before freezing. Viability of cells were reduced directly proportional in samples that took longer to be cryopreserved (93.9 vs. 96.6\%, $p=0.001)$, by contrast, CD34+ count did not differ significant at shorter or longer times of cryopreservation. In conclusion, the delay in transport time and in processing reduce the umbilical cord units quality, consequently, the time of transport and storage previous to cryopreservation must be reduced less than $36 \mathrm{~h}$.
\end{abstract}

Keywords: Cord Blood, Viability, CD34+, Cryopreservation

\section{Introduction}

Umbilical cord blood (UCB) represents a growing and consolidated source of stem cells for transplant procedures. UCB, which contains hematopoietic stem and progenitor cells, has been successfully used as an allogeneic stem cells source to treat a variety of genetic, hematologic, immunologic, and oncologic disorders for related and unrelated transplantation in children and adults patients. UCB donations are collected, stored, and made available to accredited transplant centers. The UCB banks must be dynamic, standardized and have high-quality in their cryopreserved units which could be influence by the running time before cryopreservation. [1-3].

CD34+ cells are present not only in stem cells from bone marrow and cord blood, but also in endothelial precursors, mast cells, a subpopulation of dendritic cells and soft tissue tumor cells. [4-6] The importance of the number of CD34+ cells in the success of stem cell transplantation has been repeatedly shown $[7,8]$ and so, their identification and quantification constitutes a mandatory standard for UCB banks and transplant centers $[9,10]$.

The UCB units have been processed using a modification of a triple bag system, in which these units are separated by two centrifugation steps into three components: buffy coat, red cell and plasma fractions. This processing method allows for the maintenance of sterility, volume reduction and separation of red blood cells without a significant loss of stem cells. The UCB units arrive daily from different places in the region and separated by variable distances (from 0.5 to $343 \mathrm{Km}$ ).

In the present study, we determine the influence of elapsed time from collection to cryopreservation, evaluating the percentage of viability and total number of CD34+ cells as indicator of the UCB quality.

\section{Material and Methods}

\subsection{Cord Blood Units}

A total of 2134 units were analyzed, coming from 36 Spanish authorized hospitals in Andalusia, for a six months period. All the procedures related to the collec- 
tion, processing and conservation of the UCB units were performed according to the NETCORD standards [9]. 1362 units were processed and the remaining did not reach the criteria to be cryopreservated $[9,10]$, because of low cell count, low volume, delayed arrival to the bank, bug-processing.

In this study, 150 units were randomly selected and were analyzed the following variables: type and duration of labor, day and time of collection, hospital of origin, time from collection of the unit to leave the maternity hospital, time from the hospital to the UCB bank, and the running time in the bank before cryopreservation.

\subsection{Assessment of Viability and CD34+ Cells}

Briefly, $0.5 \mathrm{ml}$ sample of UCB unit before cryopreservation was analyzed using the stem kit supplied by Beckman Coulter, including $20 \mu \mathrm{L}$ of 7-aminoactinomycin D (7-AAD) and either $20 \mu \mathrm{L}$ of CD34-phycoerythrin (PE; 580 clone)/CD45-fluorescein isothiocyanate (FITC; J33 clone) at room temperature for 20 minutes in the dark. Two milliliters of $10 \%$ ammonium chloride was added to the tubes, which were incubated for 10 minutes in the dark, and then $100 \mu \mathrm{L}$ of beads (Stem-Count, Beckman Coulter) was added. Within 1 hour of sample preparation, flow cytometric analysis was performed on a flow cytometer (EPICS XL-MLC, Beckman Coulter) with automated software (stemONE, Beckman Coulter).

\subsection{Statistical Analysis}

All the statistical analyses were made with nonparametric tests. Data was expressed as median and interquartile range. Comparisons of medians for quantitative variables were done by the Mann-Whitney test and Kruskal-Wallis. The Pearson's correlation coefficient was used to estimate the correlation between quantitative variables. All reported $\mathrm{P}$ values represent two-tailed tests, with values of 0.05 or less considered statistically significant. The statistical analysis was performed using the SPSS program, version 11.5.

\section{Results}

In our series, the cell viability was $94.9 \%$ (79.3 - 99.7). The median time spent from harvest to cryopreservation was $27.9 \mathrm{~h}$ (5.3 - 47.6). It could be divided in three independent periods (Figure 1(a)): the time from harvest to the moment of leaving the hospital (hospital time, HT), which took a median of $12.3 \mathrm{~h}(0.1$ - 28.8); the time spent in carrying the unit to the bank (transport time, TT), which was $1.8 \mathrm{~h}(0.1$ - 20.6); and, once arrived to the UCB bank, freezing was performed in $12.3 \mathrm{~h}(1-29.7)$ (bank time, BT). Only 7\% of the whole time to cryopreservation corresponded to the TT, whereas a $46 \%$ was recorded in HT and a $47 \%$ in BT (Figure 1(b)). When

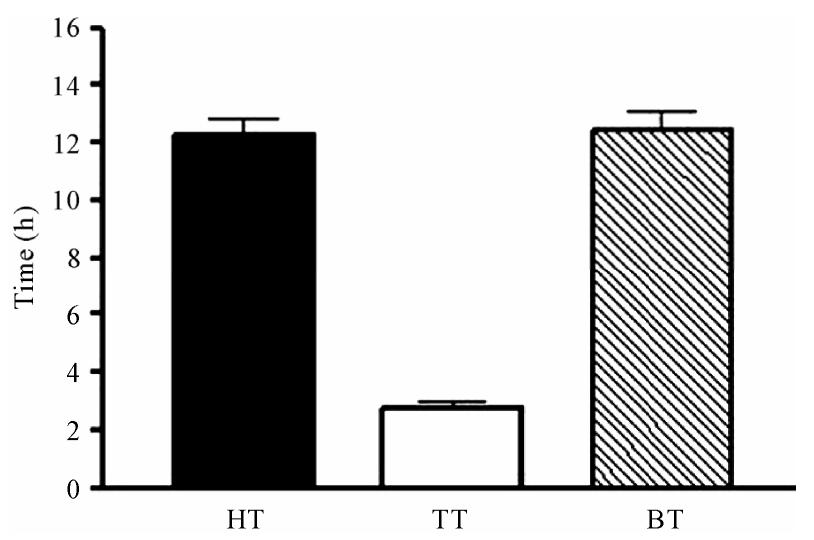

(a)

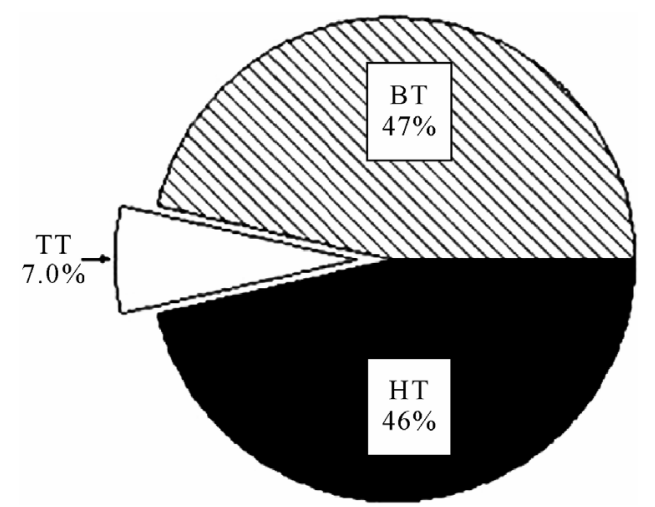

(b)

Figure 1. (a) Time from harvest to cryopreservation (represented in hours), separated in different periods: time from harvest to the moment of leaving the hospital (hospital time, HT), time of transport (TT) and time spent from the arrival to the UCB bank until freezing (bank time, BT). (b) Time (expressed as percentage of the total time to cryopreservation) spent in the different periods analyzed.

data was analyzed considering the distance of hospitals to the bank, a significant increase in time was found in farther units, mainly due to TT and BT (Kruskal-Wallis test), whereas HT remained very homogeneous at any distance.

The time to cryopreservation, including the three periods, was significantly correlated with the cell viability (Figure 2(a)), however the CD34+ counts showed only a tendency to decrease in this period (Figure 2(b)). When we compared the units with longer time to cryopreservation (more than $36.6 \mathrm{~h}, 75$ percentile) and shorter time (less than 19.9 h, 25 percentile) to cryopreservation was confirmed that those with longer periods showed significantly less viability (93.9\% vs 96.6\%, p = 0.001) (Figure 3(a)), whereas there were no significant differences in the number of CD34+ cells (15.6 vs $17.8, \mathrm{p}=1.0$ ), as shown in Figure 3(b).

As expected, most of the samples with shorter times to 


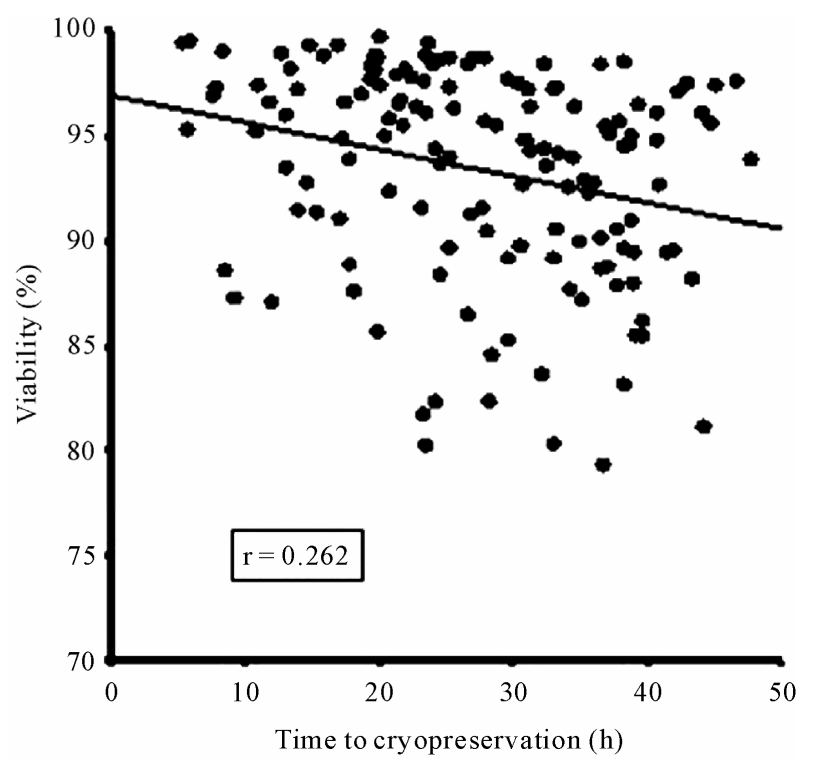

(a)

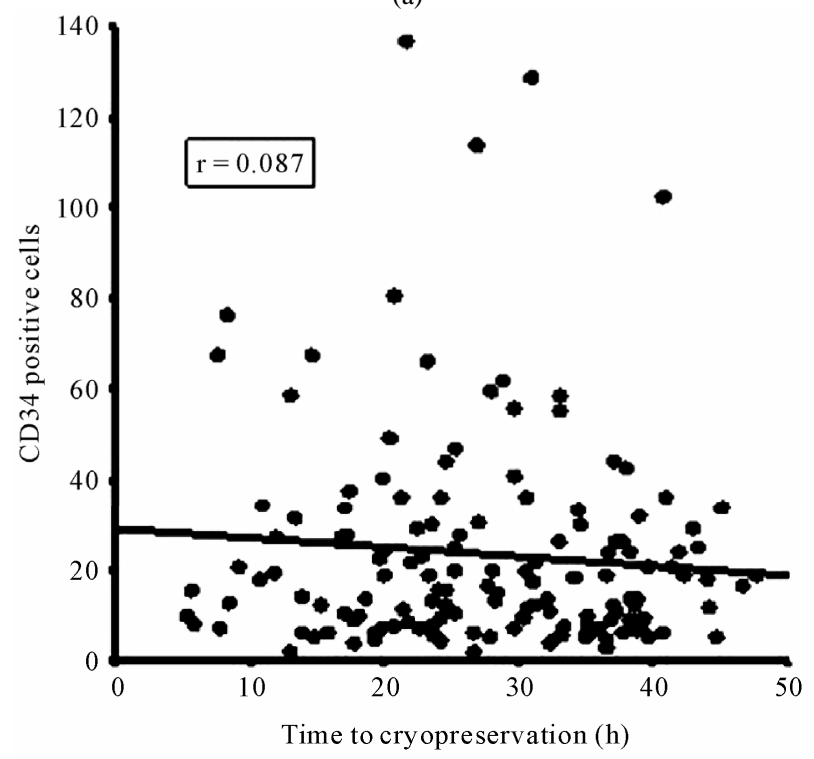

(b)

Figure 2. Correlation between the time to cryopreservation and the viability (a) or the number of CD34+ cells (b). No significant correlation was found between these variables.

cryopreservation came from hospitals close to the bank; therefore, the distance from the hospitals to the UCB bank was significantly higher in the group taking a longer time (47 vs. $163 \mathrm{Km}$, p < 0.001).

However, not only the transport time contributed to prolong the time to cryopreservation, but all the three involved periods (HT, TT and BT) were significantly longer in the 75 percentile group (Figure 4).

\section{Discussion}

Quality criteria of umbilical cord blood progenitor cells

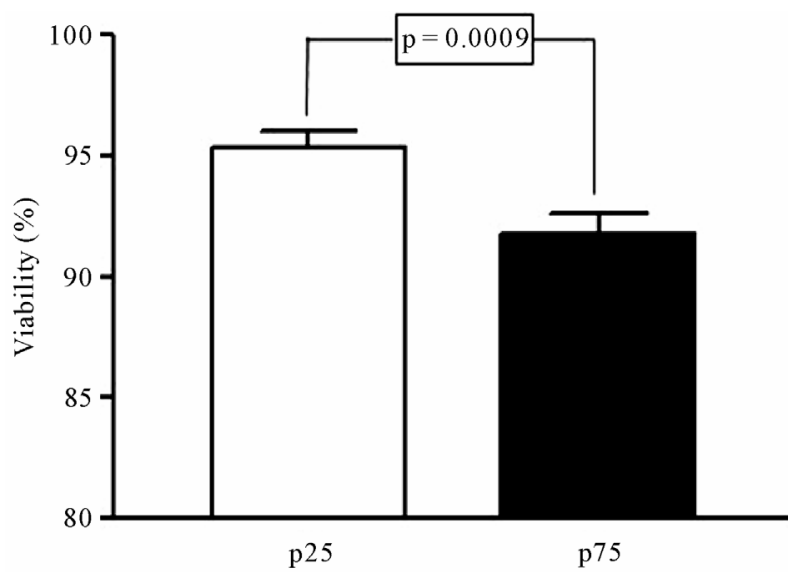

(a)

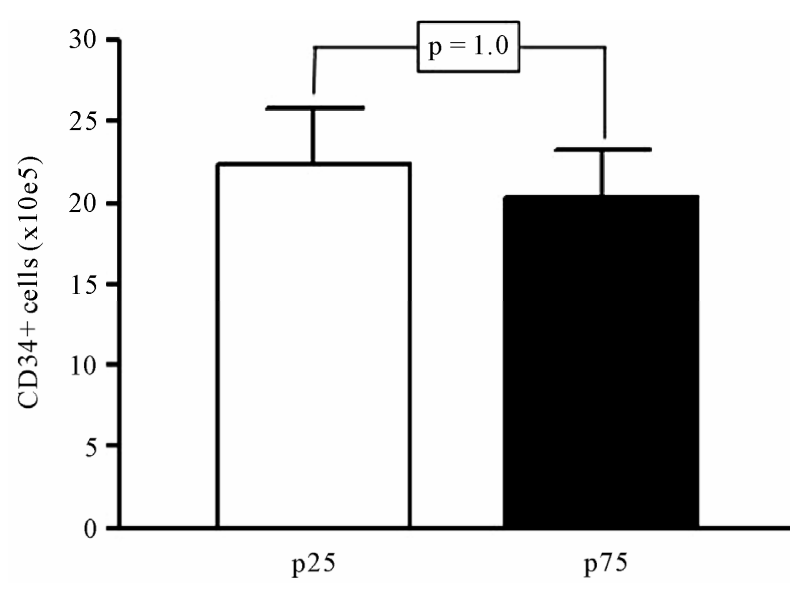

(b)

Figure 3. Analysis of the viability (a) and the number of CD34+ cells (b) in UCB samples with extreme times to cryopreservation. Samples below the 25 percentile (p25) and above the 75 percentile (p75) were selected $(n=36$ in each group) and compared by Mann Whitney test. Significance is depicted in each graph.

cryopreserved are usually very stringent. In fact, about one third of the UCB units arriving at our Center become refused because they do not achieve all the basic established criteria to be banked, mostly related to low cell count, low volume or bug-processing. Both the viability and the CD34+ cell number represent quality features of UCB samples, since they can influence the final outcome of a transplant $[8,11,12]$. In this study, we propose to analyze how the running time before cryopreservation could influence in the quality of the units emphasizing in the time related to the transport procedure, in order to improve them, if possible, in future protocols. We included samples received from different hospitals with variable distances to the UCB bank, sharing the same procedures for collection and storage. Viability and CD34+ cells are used as quality measures, and should be included 


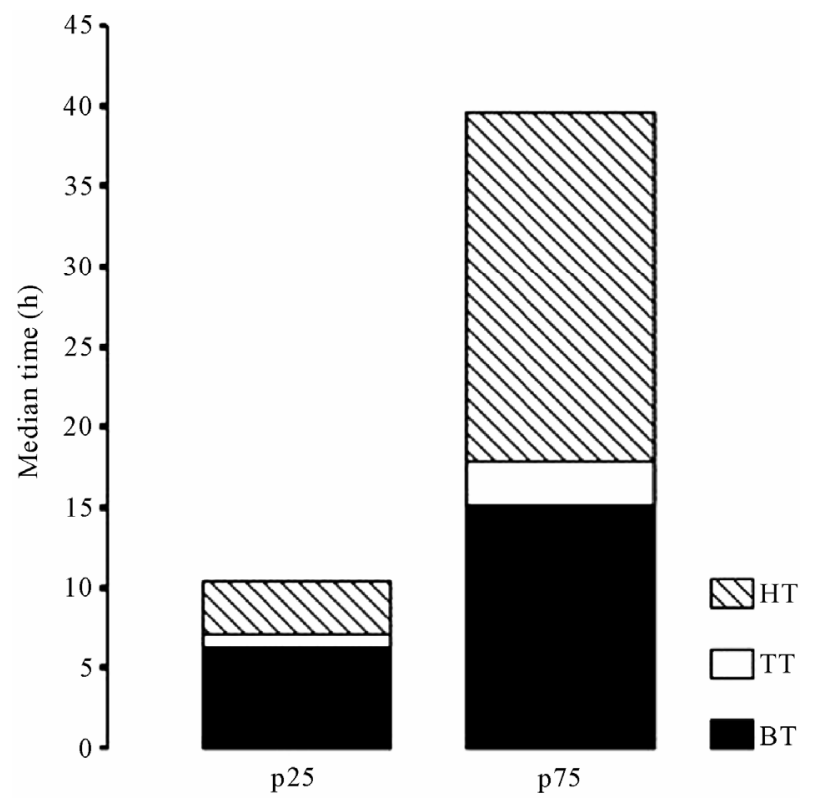

Figure 4. Differences between the 25 (p25) and 75 (p75) percentiles in the time to cryopreservation and its components (represented in hours).

in the routine processing of the units $[2,4,6]$. Other methods, such as counting of mononuclear cells (MNC) or colony forming cells (CFC) have also been frequently used [1-4,13], but the first one does not predict the results after transplantation as well as CD34+ [7, 11,12], and the second is technically more complex and cannot be used as a routine screening for hundreds of units. Furthermore, a good correlation can be found between the measurement of CD34+ cells and the nuclear total cells in the unit [6].

Our data show that a delay over $36.6 \mathrm{~h}$ (75 percentile) is associated to a significantly lower viability of the units [14]. In our series, the accuracy of the method using 7-AAD determination allows the detection of small variations (around 4\%), mostly when extreme times are compared (25 and 75 percentiles). The consequence of a decrease in viability is not clear, since some studies do not find any impairment in the expansion potential of hematopoietic cells, even with greater reductions in viability $[14,15]$.

On the other hand, CD34+ cell number was not significantly affected by the time to cryopreservation. Some authors have found a small negative correlation between the number of CD34+ cells and the time from collection to processing [16]; and other have confirmed the effect of delay in freezing in the percentage of CFU-GM [17]. However, CD34+ cells seem less sensitive to external handling; indeed, the thawing process have been shown to reduce the viability of total nucleated cells, whereas the amount of CD34+ cells remained less affected [18], with high correlations between the CD34+ number before freezing and after thawing [13].

Distance from the UCB bank was the main cause of delay in cryopreservation. However, such delay was not only produced by prolongation of the TT (significant mainly at extreme values), but also by longer BT, pointing out to a potential way of improvement (reducing the time to freeze inside the UCB bank). The arrival to the bank out of the working time may explain the delay in the processing of more distant units. The role of variables related with the mother, the baby, the labor or the pregnancy in UCB parameters has been investigated, but there is some controversy about the influence of these variables in the final quality of the unit $[16,19,20,21]$ and in our series none of the recorded variables of this type was significantly related with the viability or the CD34+ cells.

In conclusion, the delay in transport and processing may reduce the quality of the samples accepted for cryopreservation, by decreasing their viable cells. Therefore, the time of transport and storage before cryopreservation should be reduced as much as possible less than $36 \mathrm{~h}$.

\section{Acknowledgements}

We thank Dr. Manuel Barrios (Department of Haematology, Hospital Carlos Haya, Malaga, Spain) for help with the stadistical analysis.

\section{REFERENCES}

[1] F. Beaujean, J. Pico, F. Norol, M. Divine, C. Le Forestier and N. Duedari, "Characteristics of Peripheral Blood Progenitor Cells Frozen after 24 h of Liquid Storage," Journal of Hematotherapy, Vol. 5, No. 6, 1996, pp. 681686. doi:10.1089/scd.1.1996.5.681

[2] U. F. Koenigbauer, S. R. Burger and J. McCullough, "Non-Frozen Preservation of Umbilical Cord Blood," Transfusion, Vol. 42, No. 10, 2002, pp. 1383-1384. doi:10.1046/j.1537-2995.2002.00259.x

[3] A. Hubel, D. Carlquist, M. Clay and J. McCullough, "Short-Term Liquid Storage of Umbilical Cord Blood," Transfusion, Vol. 43, No. 5, 2003, pp. 626-632.

[4] S. J. Fasouliotis and J. G. Schenker, "Human Umbilical Cord Blood Banking and Transplantation: A State of the Art," European Journal of Obstetrics \& Gynecology and Reproductive Biology, Vol. 90, No. 1, 2000, pp. 13-25.

[5] K. J. Moise, "Umbilical Cord Stem Cells," Obstetrics \& Gynecology, Vol. 106, No. 6, 2005, pp. 1393-1407. doi:10.1097/01.AOG.0000188388.84901.e4

[6] P. Solves, F. Carbonell-Uberos, V. Mirabet, R. Roig, "CD34+ Cell Content for Selecting Umbilical Cord Blood Units for Cryopreservation,” Transfusion, Vol. 47, No. 3, 2007, pp. 552-553. doi:10.1111/j.1537-2995.2006.01149.x

[7] M. Eapen, P. Rubinstein, M. J. Zhang, C. Stevens, J. 
Kurtzberg, A. Scaradavou, F. R. Loberiza, et al., "Outcomes of Transplantation of Unrelated Donor Umbilical Cord Blood and Bone Marrow in Children with Acute Leukaemia: A Comparison Study,” Lancet, Vol. 369, No. 9577, 2007, pp. 1947-1954.

[8] M. J. Sullivan, "Banking on Cord Blood Stem Cells," Nature Reviews Cancer, Vol. 8, No. 7, 2008, pp. 254-263. doi:10.1038/nrc2418

[9] NETCORD FACT, "International Standards for Cord Blood Collection, Processing, Testing, Banking, Selection and Release,” 3rd Edition, FAHCT Accreditation Office, Omaha, 2006.

[10] Comité de Acreditación en Transfusión (CAT), “Estándares de Acreditación en Obtención, Procesamiento, Almacenamiento y Distribución de Progenitores Hematopoyéticos de cordón Umbilical,” 3rd Edition, Grupo Acción Médica, Madrid, 2007.

[11] J. E. Wagner, J. N. Barker, T. E. DeFor, K. S. Baker, B. R. Blazar, C. Eide, A. Goldman, et al., "Transplantation of Unrelated Donor Umbilical Cord Blood in 102 Patients with Malignant and Nonmalignant Diseases: Influence of CD34 Cell Dose and HLA Disparity on Treatment-Related Mortality and Survival,” Blood, Vol. 100, No. 5, 2002, pp. 1611-1618.

[12] S. Terakura, E. Azuma, M. Murata, et al., "Hematopoietic Engraftment in Recipients of Unrelated Donor Umbilical Cord Blood Is Affected by the CD34+ and CD8+ cell Doses," Biology of Blood and Marrow Transplantation, Vol. 13, No.7, 2007, pp. 822-830. doi:10.1016/j.bbmt.2007.03.006

[13] A. I. Flores, D. H. McKenna, M. A. Montalban, T. Kumamoto, M. Hirayama, Y. Atsuta, Y. Kodera, et al., "Consistency of Initial Cell Acquisition Procedure is Critical to the Standardization of CD34+ Cell Enumeration by Flow Cytometry: Results of a Pairwise Análisis of Umbilical Cord Units and Cryopreserved Aliquots,” Transfusion, Vol. 49, No.4, 2009, pp. 636-647.

[14] A. Brand, H. Eichler, Z. M. Szczepiorkowski, J. R. Hess, R. Kekomaki, D. H. McKenna and D. Pamphilon, "Vi- ability Does Not Necessarily Reflect the Hematopoietic Progenitor Cell Potency of a Cord Blood Unit: Results of Aninterlaboratory Exercise,” Transfusion, Vol. 48, No. 3, 2008, pp. 546-549.

[15] A. E. Beshlawy, H. G. Metwally, K. A. Khalek, R. F. Hammoud and S. M. Mousa, "The Effect of Freezing on the Recovery and Expansion of Umbilical Cord Blood Hematopoietic Stem Cells," Experimental and Clinical Transplantation, Vol. 7, No. 1, 2009, pp. 50-55.

[16] R. Nakagawa, T. Wanatabe, Y. Kawano, S. Kanai, H. Suzuya, M. Kaneko, H. Watanabe, et al., "Analysis of Maternal and Neonatal Factors that Influence the Nucleated and CD34+ Cell Yield for Cord Blood Banking," Transfusion, Vol. 44, No. 2, 2004, pp. 262-267.

[17] A. A. Shlebak, S. B. Marley, I. A. G. Roberts, R. J. Davidson, J. M. Goldman and M. Y. Gordon, "Optimal timing for Processing and Cryopreservation of Umbilical Cord Haematopoietic Stem Cells for Clinical Transplantation,” Bone Marrow Transplant, Vol. 23, No. 2, 1999, pp. 131-136.

[18] J. Miura, M. Minegishi, T. Itoh, T. Kitaura, N. Fukawa, H. Takahashi, A. Suzuki, et al., "Quality Evaluation of Umbilical Cord Blood Progenitor Cells Cryopreserved with a Small-Scale Automated Liquid Nitrogen System," Cryobiology, Vol. 57, No. 2, 2008, pp. 178-181.

[19] K. K. Ballen, M. Wilson, J. Wuu, A. M. Ceredona, C. Hsieh, F. M. Stewart, M. A. Popovsky, et al., "Bigger Is Better: Maternal and Neonatal Predictors of Hematopoietic Potential of Umbilical Cord Blood Units,” Bone Marrow Transplant, Vol. 27, No. 1, 2001, pp. 7-14. doi:10.1038/sj.bmt.1702729

[20] S. Redzko, J. Przepiesc, J. Zak, J. Urban and J. Wysocka, "Influence of Perinatal Factors on Hematological Variables in Umbilical Cord Blood," Journal of Perinatal Medicine, Vol. 33, No. 1, 2005, pp. 42-45. doi:10.1515/JPM.2005.007

[21] P. Solves, "Stress Factor and Umbilical Cord Blood Banking,” Transfusion Medicine, Vol. 17, No. 3, 2007, pp. 205-206. 